\title{
Seismic Performance of Elevated Reinforced Concrete Water Tanks
}

\author{
Sandesh Sagar Tripathi ${ }^{a}$, Kamal Bahadur Thapa ${ }^{b}$ \\ a Department of Urban Development and Building Construction, Government of Nepal \\ b Department of Civil Engineering, Pulchowk Campus, Institute of Engineering, Tribhuvan University, Nepal \\ Corresponding Author: ${ }^{b}$ kamal.thapaeioe.edu.np
}

Received: 2020-08-20

Revised: 2021-02-25

Accepted: 2021-02-26

\begin{abstract}
:
Most of the codal provisions used worldwide for the design of elevated water tanks incorporates the nonlinear response through reduction factor that considers overstrength, ductility and redundancy. The majority of these codes provide a value which incorporates the demand of their geological condition and construction industry. In Nepal, there is lack of own guidelines and codes for the seismic design of elevated water tanks. In the present work, seismic performance of elevated reinforced concrete $(R C)$ Intze type water tank is evaluated and value of the response reduction factor $(R)$ for the design of such tank is determined. In this research work 34 models of elevated reinforced water tank were analyzed using SAP 2000 to evaluate the seismic performance with varying tank filling condition and staging height for 450 cumec and 225 cumec capacity. Based on the results, it is concluded that single value of response reduction factor cannot be justified for all heights and capacity of elevated RC water tank. So, for economical design purpose, estimation of response reduction factor with exact analysis is preferred.
\end{abstract}

Keywords: Elevated RC water Tank, Seismic Performance, Response Reduction factor, Intze type tank

\section{Introduction}

Elevated water tanks is considered as one of the lifeline structures because it serves as a provider of potable water as well as firefighting operations even during emergency condition. The failure and malfunction of such water storage facility disrupts the emergency response and recovery immediately after earthquakes. In recent years, Nepalese civil engineers has developed considerable interest in the seismic performance evaluation of elevated water tank, especially of reinforced concrete. This is due to the fact that elevated $\mathrm{RC}$ water tanks during earthquakes get damaged leading to complete collapse.

Many elevated water tanks have not performed up to expectation in many earthquake in past. The poor performance of these structures in many earthquakes such as Jabalpur 1997, Chile 1960 and Gujarat 2001 has been reported [18]. Extent of damage ranges from minor cracks in the pedestal, joints, and tanks up to complete collapse of entire structures as well.
Unlike most other structures which may have uniform dead and live load during their life time, elevated tanks could experience significantly different gravity loads while working in the water system. On average, when tank is empty, the overall weight of the structures may fall to $75 \%$ of the full tank state. The change in the gravity loads adds some complication to the seismic design of elevated water tanks. Also the structural system of elevated tank is different than that of general structures as a huge mass is concentrated at the top of the structures and during severe earthquakes, even if tank survives without damages, failure or heavy damages in the staging system may result in collapse of structures. The hydrodynamic effect of water is another aspect of study which should be addressed in seismic design of elevated tanks.

The maximum force induced in the elevated water tank due to earthquake mainly depends on level of water inside the tank. Housner [14] reported that due to the effect of sloshing during earthquake, the maximum force induced in partially filled tank is significantly less 
than that induced in the full tank without freeboard. The actual forces may be as little as $1 / 3$ of the force anticipated on the basic of a completely filled tank [14]. The elevated water tank shall perform well especially during earthquake. For this, an appropriate value of performance factor (say 3) is to be taken for the calculation of seismic design forces for elevated water tanks [10].

Jaiswal and Jain [13] studied limitations and shortcomings in the provisions of IS 1893-1984. Jain and Medhekar [9], Jain and Sameer [11] provided a set of provisions on a seismic design of liquid storage tanks to propose values of response reduction factor for different types of tanks.

Jaiswal et al. [12] had reviewed on provisions of IBC 2000, ACI, AWWA, API, Eurocode 8 and NZSEE guidelines. Liquid storage tanks possess low ductility and energy absorbing capacity as compared to conventional buildings. Depending on the type of tank, design seismic force for the tank can be 3 to 7 times higher than that for buildings. Convective and impulsive components need to be considered in the seismic analysis of tanks. However, the inclusion of convective mode of vibration in the seismic analysis of elevated water tanks is highly suggested. Moreover, the range of values of response reduction factor for different types of tanks should be 1.1 to 2.25. For a particular type of tank with short period (less than 0.6s) ratio of base shear of tank and buildings is almost same in all codes. However for tanks with time period greater than $0.6 \mathrm{~s}$, there is large variation in the values of this ratio obtained from different codes. This is attributed to use of spectra of different shapes of building and tanks [12]. In recently published version of Nepal National Building Code 105:2020 [16] as well the concept of various element of Response reduction factor has been introduced but the specific provision for special structures like elevated reinforced water tank is still absent.

The objective of this paper is to evaluate the seismic performance of various elevated reinforced concrete (RC) water tanks constructed in Nepal. Nonlinear static pushover analysis was carried out to determine the response reduction $(\mathrm{R})$ factor required for the seismic design of such structures. Intze type tanks of varying tank sizes, various tank filling conditions and different stage heights are considered in the analysis. Overstrength and ductility factor are calculated by considering the effect of various critical parameters such as tank capacity and fundamental period. ATC 19 (1995) methodology is adopted to propose the response reduction factor $(\mathrm{R})$ for $\mathrm{RC}$ elevated water tank.

\section{Theoretical Approach}

Well-detailed seismic framing systems are capable of sustaining large inelastic deformations without collapse (ductile behavior) and thus develop lateral strength in excess of their design strength (often termed as reserved strength). This is the concept of response modification factor (R), which was first proposed by the Applied Technology council (ATC) in the ATC-3-06 report published in 1978. The $\mathrm{R}$ factor is defined as the ratio of the forces that would develop under the specified ground motion if the framing system were to behave entirely elastically (Ve) to prescribed design forces at the strength level (Vd). The Response Reduction factor $(\mathrm{R})$ is expressed as the product of three factors such that

$$
R=R_{S} \times R_{\mu} \times R_{R}
$$

where, $R_{S}, R_{\mu}$, and $R_{R}$ are strength, ductility and redundancy factors, respectively. Nonlinear static analysis (also termed as pushover analysis) can be used to estimate the strength of any framing system. Ductility factor is a measure of the nonlinear response of the complete framing systems and not the components of framing system, regardless of which ductility parameter is used. According to ATC 19, response modification factor must be reduced for the structural systems with low level of redundancy. The proposed value of redundancy depending upon the lines of vertical seismic framing are given in table of ATC-19. The three components of $\mathrm{R}$ are defined below.

Overstrength Factor, $R_{S}=\frac{V_{y}}{V_{d}}$

Ductility Factor, $R_{\mu}=\frac{\mu-1}{\varphi}+1$

(Using Miranda and Betero Formulation)

$\phi=1+\frac{1}{12 T-\mu T}-\frac{2}{5 T} e^{-2(\ln (T)-0.2)^{2}}$ 
Redundancy Factor, $R-R$ is defined as per ATC-19.

\section{Description of Water Tank}

The elevated water tank considered for this study are typical Intze type RC elevated water tank of 450 cumec and 225 cumec capacity which are commonly constructed in terai region of Nepal. Different assumptions are made to reduce the complexity without much variation in model and real structure. Following section describes the assumptions made during the modeling of water tank.

- Foundation: It is assumed that there is no soil structure interaction i.e. foundation is assumed to be rigid. All six degree of freedom are fixed in order to assume a fully restrained structure at the base.

- Participating Elements: Only Primary components like beam, column, dome and cylindrical wall are modeled. Effect of secondary and non-structural components like staircase, gallery etc. are assumed to be negligible.

- The effect of staging and tank filling condition is seen by taking a fixed dimension of tank and staging for each capacity of tank.

- Secondary effects such as temperature, creep, shrinkage etc. are not considered to simplify the analysis process.

Different models were created changing the parameter of elevated water tank considering each combination based on following scope.

- Only Intze type RC elevated water tank of 225 and 450 cumec capacity are considered in study.

- Tank with empty condition, Half-filled condition and Fully -filled condition are modeled.

- The study was limited to two capacity, three filling condition as mentioned above and four stage height i.e. $12 \mathrm{~m}, 16 \mathrm{~m}, 20 \mathrm{~m}$ and $24 \mathrm{~m}$ of elevated water tank.

The grade of concrete and steel used are M20 and Fe415, respectively. IS 456:2000 is used for the design of water tank. The geometrical properties of various components of elevated RC water tank used in study are given below:

Table 1: Geometrical Properties of Elevated water tank

\begin{tabular}{|l|l|l|}
\hline Tank Capacities & $450 \mathrm{cumec}$ & $225 \mathrm{cumec}$ \\
\hline Top Dome Thickness & $100 \mathrm{~mm}$ & $100 \mathrm{~mm}$ \\
\hline Top Ring Beam & $400 \mathrm{~mm} \times 300 \mathrm{~mm}$ & $250 \mathrm{~mm} \times 300 \mathrm{~mm}$ \\
\hline Cylindrical wall & $200 \mathrm{~mm}$ thick & $200 \mathrm{~mm}$ thick \\
\hline Bottom Ring Beam & $400 \mathrm{~mm} \times 600 \mathrm{~mm}$ & $400 \mathrm{~mm} \times 500 \mathrm{~mm}$ \\
\hline Circular Ring Beam & $500 \mathrm{~mm} \times 900 \mathrm{~mm}$ & $400 \mathrm{~mm} \times 750 \mathrm{~mm}$ \\
\hline Bottom Dome & $200 \mathrm{~mm}$ thick & $225 \mathrm{~mm}$ thick \\
\hline Conical Dome & $300 \mathrm{~mm}$ thick & $300 \mathrm{~mm}$ thick \\
\hline Braces & $400 \mathrm{~mm} \times 650 \mathrm{~mm}$ & $400 \mathrm{~mm} \times 600 \mathrm{~mm}$ \\
\hline Columns & $600 \mathrm{~mm} \times 600 \mathrm{~mm}$ & $475 \mathrm{~mm} \times 475 \mathrm{~mm}$ \\
\hline
\end{tabular}

The hydrodynamic effect of water and the calculation of loads due to the tank, bracings and columns are incorporated in the design as per IITK- GSDMA guidelines.

\section{Analysis and Modeling Approach}

\subsection{Modeling of Structure}

The foundation was assumed to be rigid and soil structure interaction effect was neglected. Column and Braced beams are modeled as two noded frame element whereas slab and wall are modeled as four noded shell element. The modeled elevated water tank is shown in Figure 1(b).

\subsection{Modeling of Water}

The impulsive and convective mass will be modeled as per GSDMA guideline. The ACI/GSDMA mechanical model has divided the total water mass into two equivalent lumped masses. One is impulsive mass and another is convective mass. Impulsive mass is that which behaves as rigidly connected to the tanks under horizontal earthquake ground motion. The mass accelerates along with wall and induces impulsive hydrodynamic pressure. Convective mass experiences sloshing effect during earthquake. The mass freely moves and exerts convective hydrodynamic pressure. The mass is connected to tank by equivalent spring having stiffness equal to sloshing stiffness of water. The convective mass, impulsive mass, their height of applications, spring stiffness required for equivalent mechanical model are calculated as per ACI/GSDMA. Flexibility of supports will be addressed by providing the equivalent stiffness value in the model. 


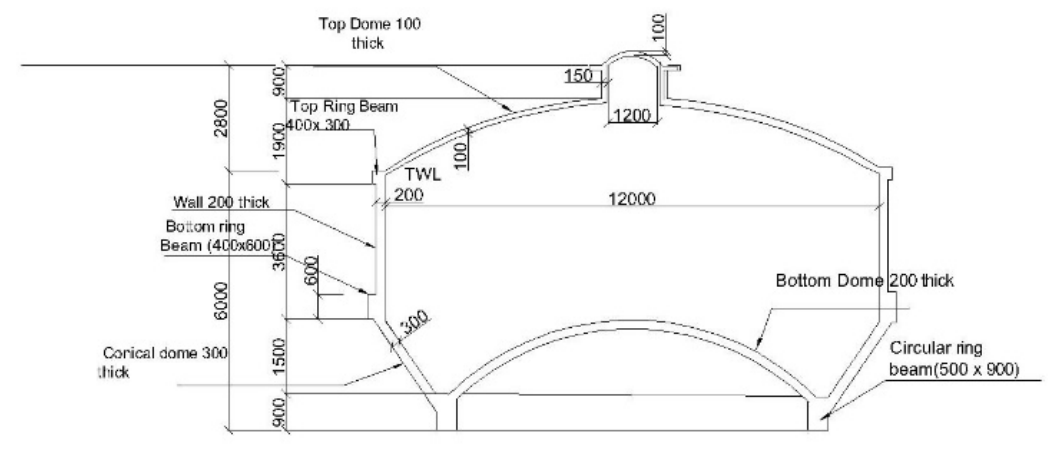

Details of tank container

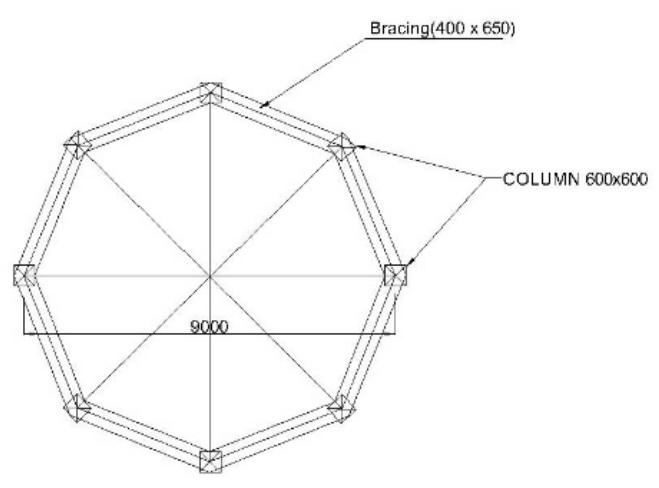

Plan of staging

(a)

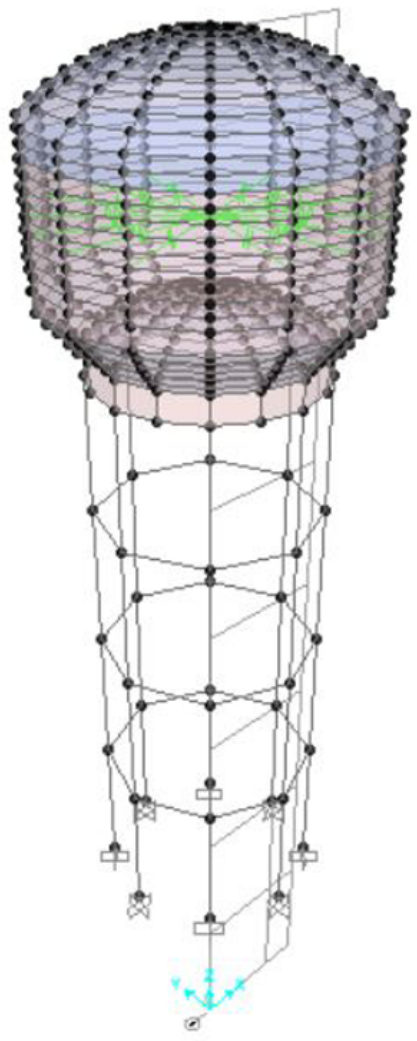

(b)

Figure 1: (a) Details and Plan of 450 cumec elevated RC tankVarying Soil Type (b) SAP model of elevated tank used for analysis

\subsection{Methodology}

The tank was designed and detailed as per codal provisions of IS 1893-2002 and IS: 13920:1993.The framing system and container is modeled in SAP2000 to perform static pushover analysis. The material non-linearity are assumed through the definition of frame hinge properties which represents the post yield behavior. Default hinge is assigned at the end of each column and bracing beam where mechanism is expected. After assigning hinge properties to the structure, the nonlinear static cases were defined. The structure was loaded with $25 \%$ of live load and dead load. The relevance of gravity loads was force-controlled whereas the relevance of lateral loads was displacement controlled. The base shear $(\mathrm{V})$ versus roof displacement $(\Delta)$ curve of the structure, usually called static pushover curve is plotted. Due to plan symmetry of structure, the Pushover is carried out in one direction only. The result obtained from the pushover Curve was used for calculation of Overstrength and Ductility factor whereas the value of redundancy factor are taken from table of ATC-19. Generally the liquid containing tanks possess low overstrength, redundancy and ductility as compared to building. In building components generally the nonstructural components substantially contribute to overstrength, in tanks such non -structural components are not present.

\section{Result and Discussions}

\subsection{Seismic Performance of Elevated Water Tank}

Various parameters for hydrodynamic analysis of the $\mathrm{RC}$ elevated water tanks are computed. The parametric value obtained as per IITK-GSDMA guidelines are presented in Table 2. 
Table 2: RC Elevated Water tank with varying stage height and tank fill condition

\begin{tabular}{|l|c|c|c|c|c|c|}
\hline \multirow{2}{*}{ Parameters } & \multicolumn{2}{|c|}{ For 450 cumec tank Capacity } & \multicolumn{2}{c|}{ For 225 cumec tank Capacity } \\
\cline { 2 - 6 } & $\begin{array}{c}\text { Tank } \\
\text { Empty }\end{array}$ & $\begin{array}{c}\text { Tank } \\
\text { Half-Filled }\end{array}$ & $\begin{array}{c}\text { Tank } \\
\text { Fully-Filled }\end{array}$ & $\begin{array}{c}\text { Tank } \\
\text { Empty }\end{array}$ & $\begin{array}{c}\text { Tank } \\
\text { Half-Filled }\end{array}$ & $\begin{array}{c}\text { Tank } \\
\text { Fully-Filled }\end{array}$ \\
\hline For 12 m staging & & & & & & \\
\hline Impulsive Time period(sec) & 0.498 & 0.533 & 0.623 & 0.462 & 0.506 & 0.609 \\
\hline Base Shear(KN) & 429.12 & 460.43 & 541.73 & 260.24 & 286.06 & 344.49 \\
\hline Base Moment(KN m) & 6354.86 & 6979.79 & 8500.39 & 3801.26 & 4227.95 & 5184.98 \\
\hline Stiffness(KN/m) & & & 51285.97 & & & 33514.61 \\
\hline For 16 m staging & & & & & & \\
\hline Impulsive Time period(sec) & 0.605 & 0.645 & 0.751 & 0.553 & 0.604 & 0.723 \\
\hline Base Shear(KN) & 364.35 & 390.84 & 459.44 & 225.05 & 247.04 & 296.41 \\
\hline Base Moment(KN m) & 6852.99 & 7489.12 & 9043.82 & 4187.55 & 4638.7 & 5645.25 \\
\hline Stiffness(KN/m) & & & 35884.13 & & & 24246.77 \\
\hline For 20 m staging & & & & & & \\
\hline Impulsive Time period(sec) & 0.7 & 0.745 & 0.865 & 0.635 & 0.691 & 0.824 \\
\hline Base Shear(KN) & 324.18 & 347.67 & 408.35 & 202.42 & 221.9 & 265.32 \\
\hline Base Moment(KN m) & 7394.19 & 8053.47 & 9669.03 & 4576 & 5053.65 & 6112.93 \\
\hline Stiffness(KN/m) & & & 27596.53 & & & 18994.26 \\
\hline For 24 m staging & & & & & & \\
\hline Impulsive Time period(sec) & 0.787 & 0.837 & 0.969 & 0.711 & 0.773 & 0.918 \\
\hline Base Shear(KN) & 296.33 & 317.74 & 372.9 & 186.39 & 204.08 & 243.2 \\
\hline Base Moment(KN m) & 7944.4 & 8631.79 & 10318.96 & 4959.28 & 5463.61 & 6574.98 \\
\hline Stiffness(KN/m) & & & 22418.81 & & & 15612.23 \\
\hline
\end{tabular}

From the parametric study of elevated water tank, the following results were observed:

- The fundamental time period increases as the height of the staging increases for each tank fill condition. In other hand, the time period of the tank also increases with increase in the quantity of the water in elevated water tank.

- The impulsive time period increases as the height of the staging increases for each tank fill condition. In other hand, the time period of the tank also increases with increase in the quantity of the water in elevated water tank. The increase in impulsive time period is due to fact that impulsive mass goes on increasing for increase in tank volume as its value depends upon the $\mathrm{h} / \mathrm{D}$ ratio which increases as the filling in tank increases. Increase in impulsive time period with increase in height of stage is due to the fact that stiffness of tank decreases as the height of stage height increases.

- The base shear increases with increase in tank fill condition for constant stage height whereas it decreases with increase in stage height for constant tank fill condition. The decrease in base shear with increase in stage height is due to dispersion of base shear with increasing stage height.

- The variation of base moment was found to be similar for tank filling condition and stage height increment. In both cases, base moment increases with increase in stage height of tank and filling condition of tank. The value of stiffness decreases as the staging height of tank increases as shown in table.

- From the study of parameters of elevated RC water tank as summarized in table 2 , it is concluded that the value of every parameter for elevated tank of 450 cumec is higher than 225 cumec but the percentage difference in value of parameters is unique.

- The Response Reduction Factor of a 450 cumec capacity elevated RC water tank with $16 \mathrm{~m}$ Staging height and tank empty condition is 4.93 . The effect of hardness of soil and earthquake zone in base shear are studied by taking 450 cumec tank with $16 \mathrm{~m}$ staging height. The value of base shear shows increasing trend for increase in earthquake zone whereas the base shear decreases with increase in hardness of soil. 


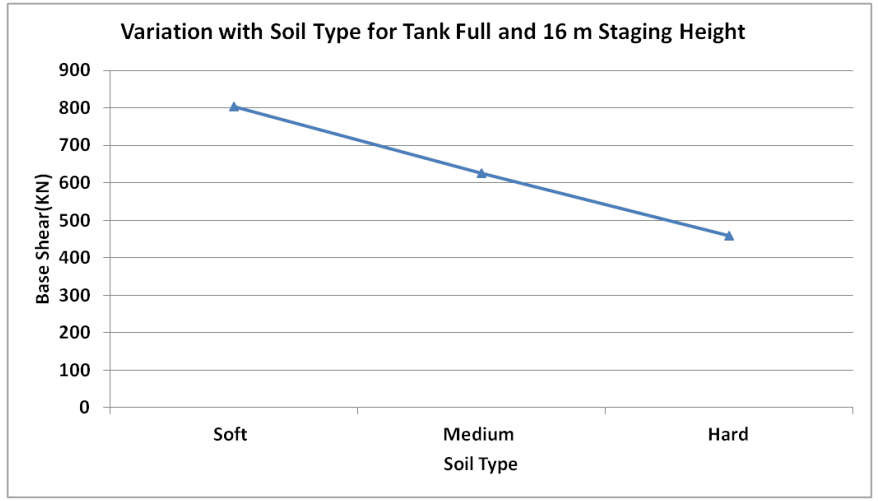

(a)

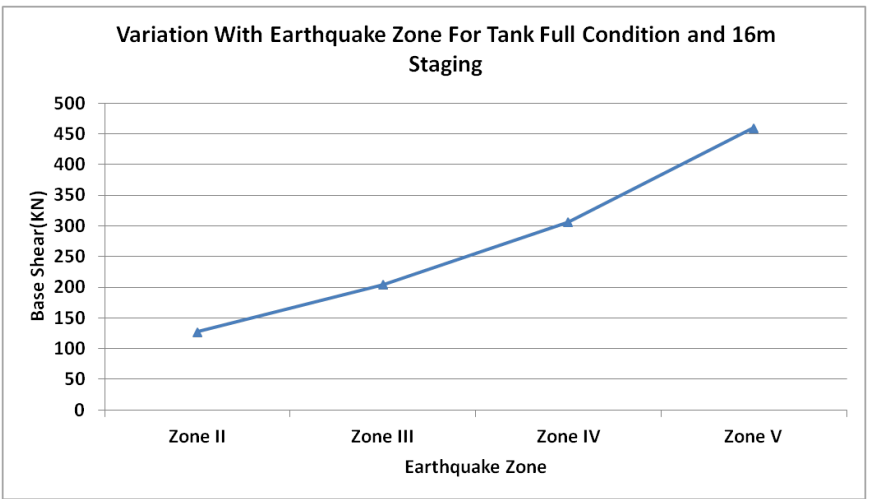

(b)

Figure 2: Variation of Base Shear for fully filled tank (450 cum capacity) of $16 \mathrm{~m}$ staging height (a) Varying Soil Type (b) Varying Earthquake Zone

\subsection{Analysis of Seismic Response Factor of Elevated Water Tank}

\subsubsection{Effect of fundamental time period on overstrength, ductility and Response reduction factor}

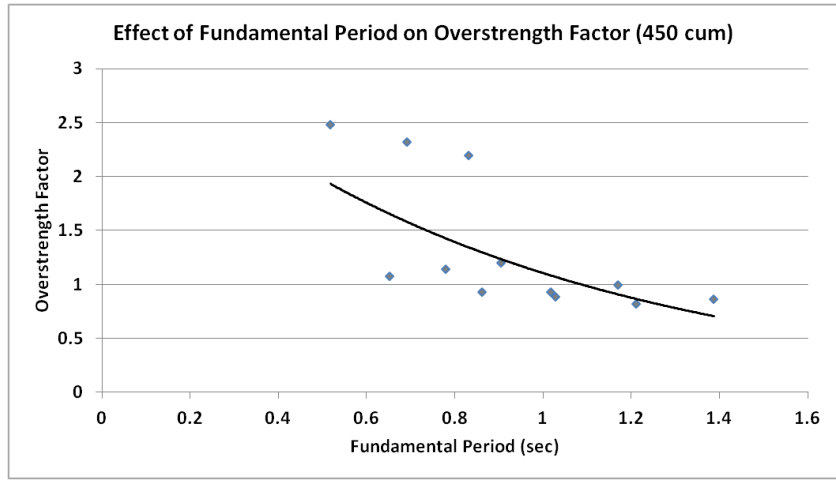

(A)

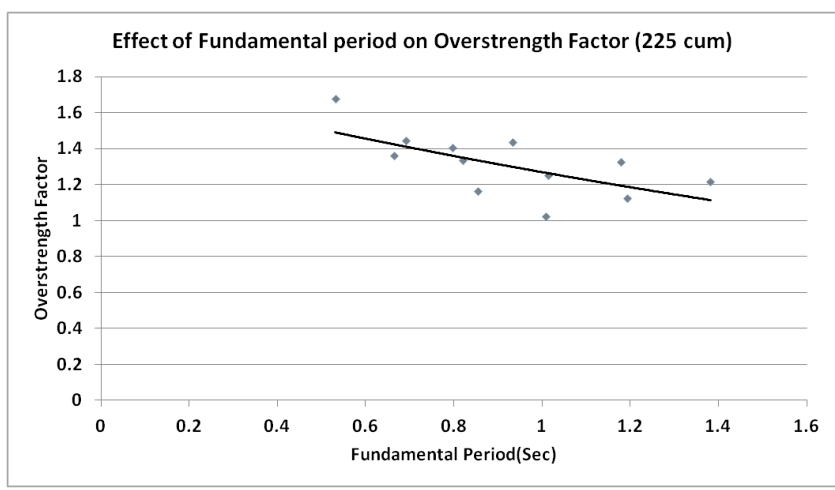

(b)

Figure 3: Variation of Overstrength Factor with Fundamental Period for (a) 450 and (b) 225 cum capacity

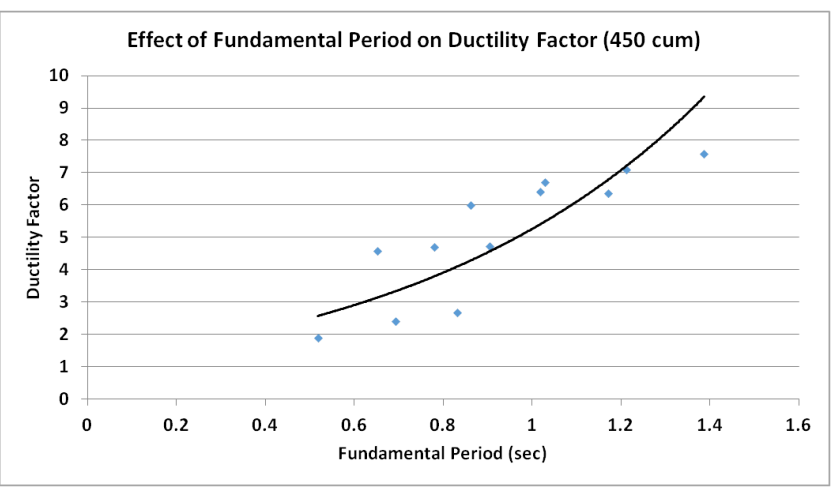

(a)

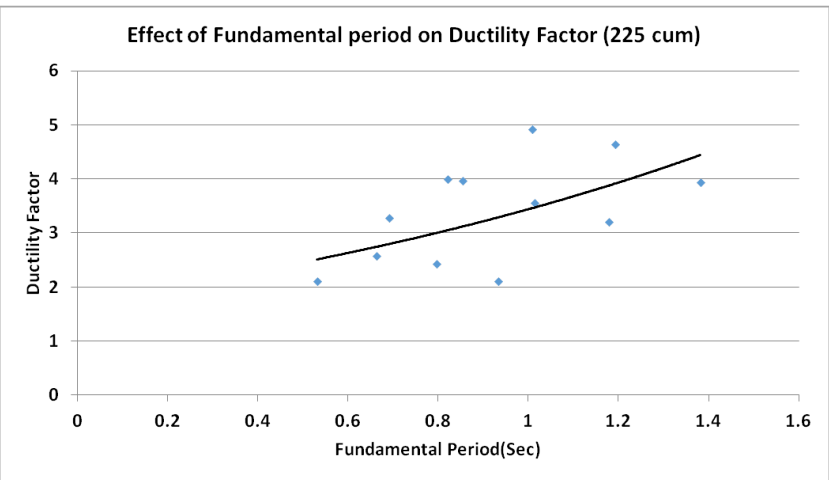

(b)

Figure 4: Variation of Ductility Factor with Fundamental Period for (a) 450 and (b) 225 cum capacity

Figs. (3), (4) and (5) respectively show the variation of overstrength, ductility and response reduction factors with fundamental period. The value of Response Reduction Factor increases when fundamental period increases as shown in Figure 4 and the variation for 225 cumec tank was higher than 450 cumec tank. Since the redundancy factor is constant for all cases and the 


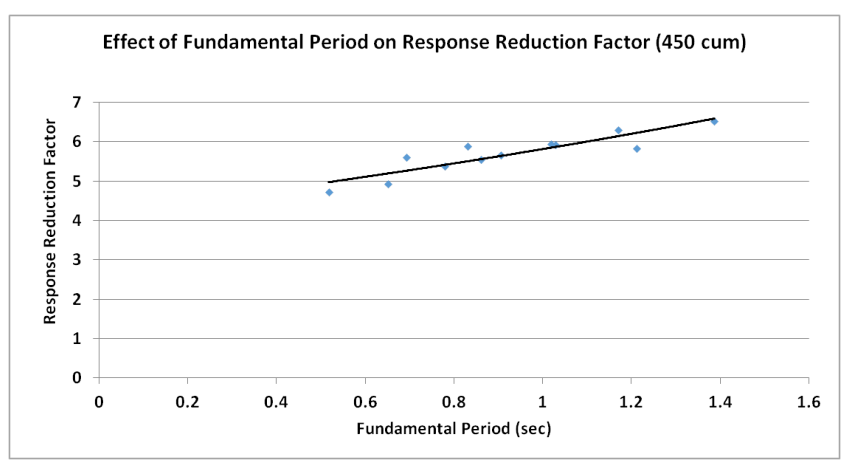

(a)

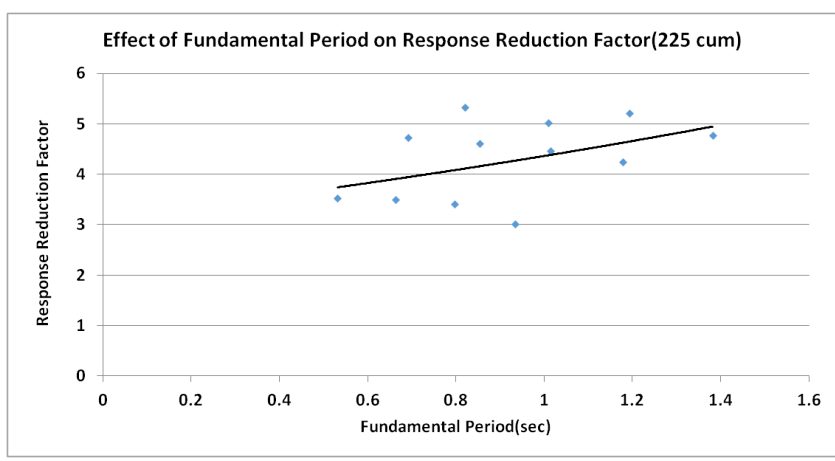

(b)

Figure 5: Variation of Response Reduction Factor with Fundamental Period for (a) 450 and (b) 225 cum capacity

overstrength factor has also decreasing trend line with the fundamental period, the increasing trend line of Response reduction factor shows that ductility factor variation trend was the deciding factor for obtaining response reduction factor for the given model under consideration.

\subsubsection{Effect of tank size, stage height and tank fill condition}

Figure 6 and Figure 7 show the effect of various parameters on overstrength, ductility and Response Reduction factors. Tank with capacity of 450 cumec demonstrates lower overstrength factor. However, it shows higher ductility factor and Response Reduction Factor than 225 cumec capacity tank. The value of ductility factor is found to be the deciding factor for the variation of Response Reduction factor. The overstrength factor goes on decreasing with increase in tank fill condition. On the other hand, the ductility factor goes on increasing with increase in tank fill condition. The value of overstrength factor shows significant decrement as the staging height increases from $12 \mathrm{~m}$ to $16 \mathrm{~m}$. In contrary, significant increase in the value of ductility factor is observed when the staging height is increased from $12 \mathrm{~m}$ to $16 \mathrm{~m}$. Response Reduction Factor increases with increase in tank fill condition for constant stage height. Since load considered in the tank empty is lower than tank-fill condition, it demands higher design force to achieve a consistent level of damage.

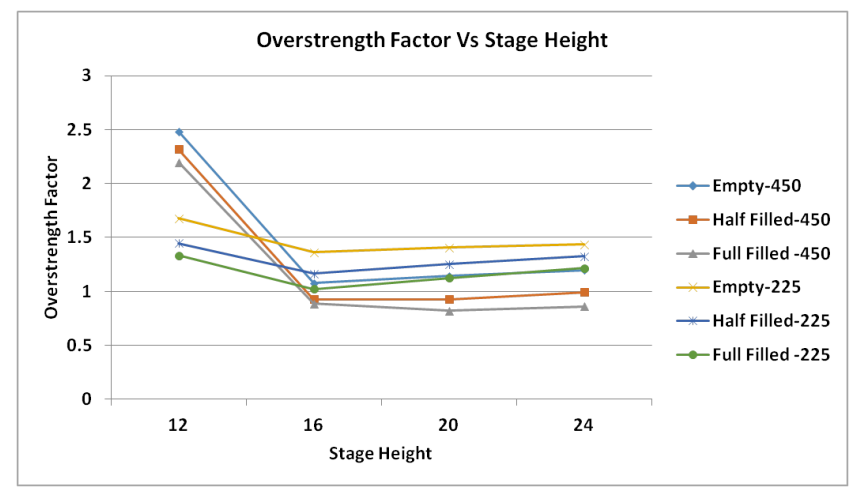

(a)

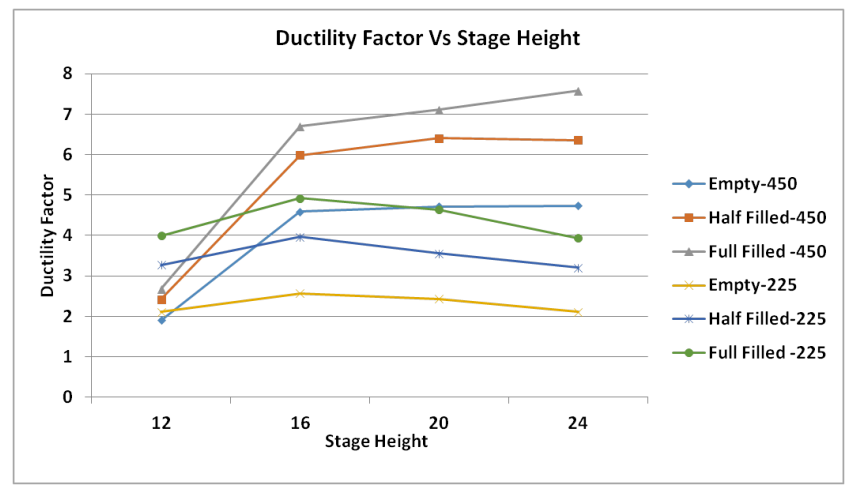

(b)

Figure 6: Variation of Overstrength factor and ductility factor with Staging Height for (a) 225 cum and (b) 450 cum capacity

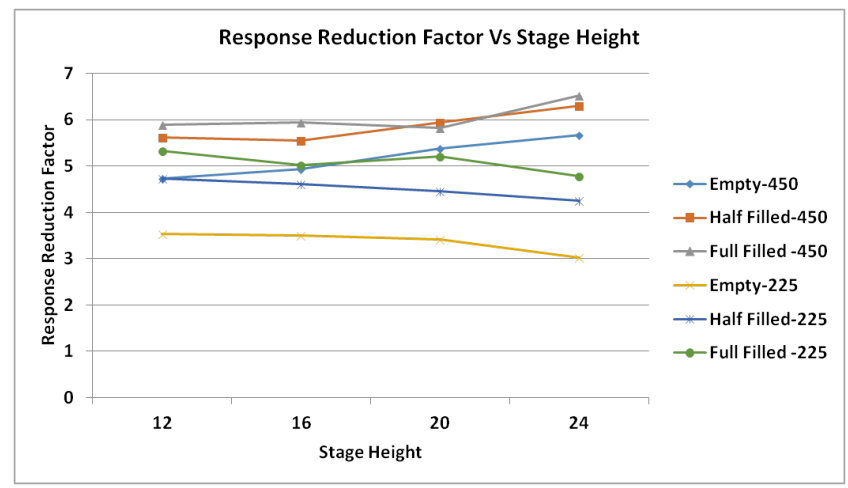

Figure 7: Variation of Response Reduction Factor with Staging Height for 225 cum and 450 cum capacity 


\subsubsection{Effect of Seismic Zones and Soil Types}

The effect of seismic zones and Soil type was studied by considering elevated water tank of $16 \mathrm{~m}$ staging height in tank full condition for 450 and 225 cumec capacity.

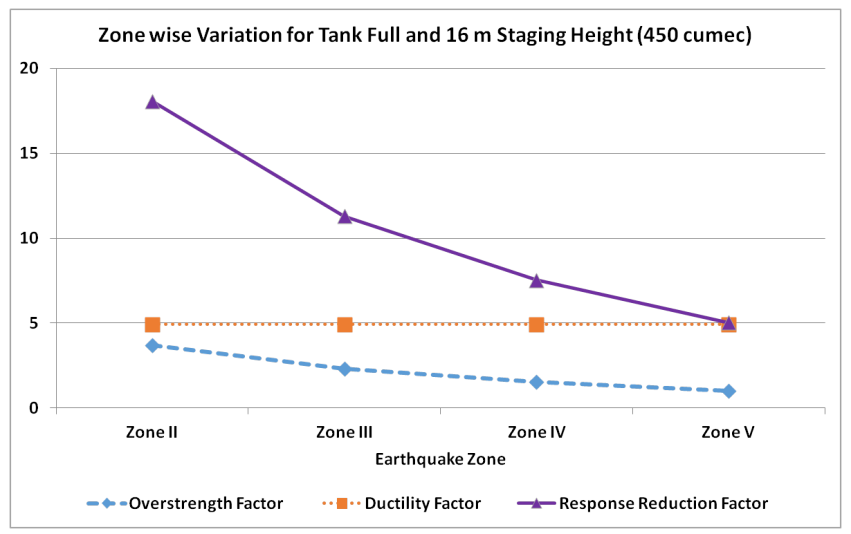

(a)

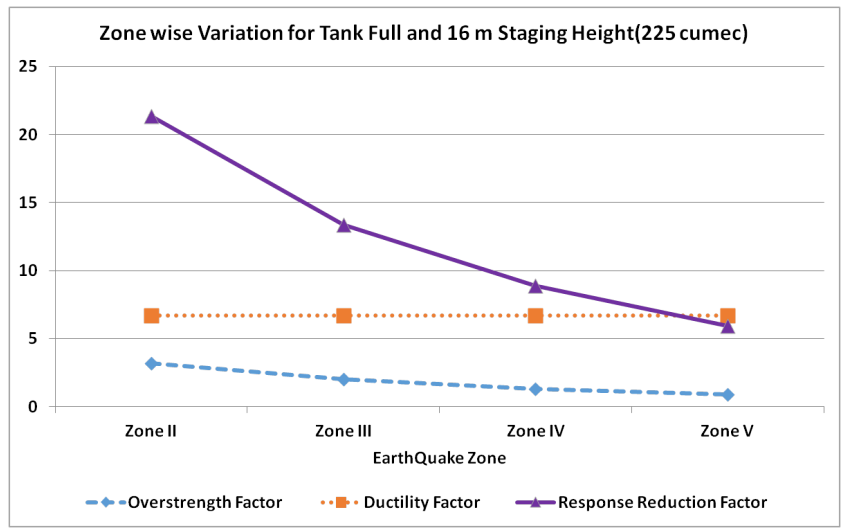

(b)

Figure 8: Variation of Overstrength, Ductility and Response Reduction Factor for (a) 450 and (b) 225 cumec capacity with varying Earthquake Zone for fully filled tank of $16 \mathrm{~m}$ staging height

Figure 8 shows that overstrength factor decreases with increase in seismic zones which ultimately decreases the response reduction factor. Figure 9 shows that overstrength factor increases with increases in hardness of soil whereas ductility factor decreases. Finally the Response reduction factor shows increasing trend for increase in soil Hardness.

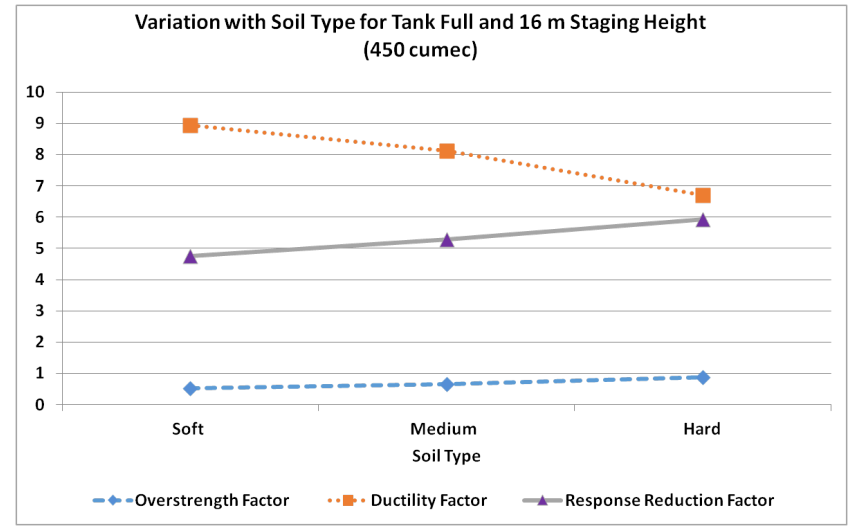

(a)

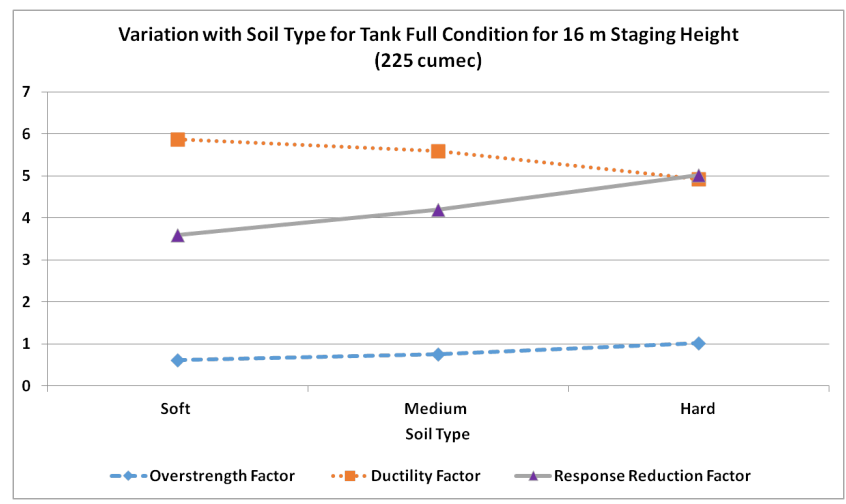

(b)

Figure 9: Variation of Overstrength, Ductility and Response Reduction Factor for (a) 450 and (b) 225 cumec capacity with varying Soil Type for fully filled tank of $16 \mathrm{~m}$ staging height

\section{Conclusions}

The main motive of this study is to determine the effect of tank size, Stage height, tank fill condition ,soil type and seismic zones on ductility and overstrength factor of Intze type of RC elevated water tank usually constructed in Nepal. Here are some conclusions drawn from the analytical investigation of data obtained.

1. The hydrodynamic parameters assessed for the cases of elevated tank under study shows that the fundamental and impulsive time period shows increasing trend as stage height increases from 12 $\mathrm{m}$ to $24 \mathrm{~m}$ and quantity of water in tank increases. Impulsive time period is more dependent on mass of water in the tank and stage height as more the water in tank more impulsive force is created in tank and increase in height of tank keeping the size of column constant decreases the stiffness of whole structure. Whereas convective time period 
decreases as the tank moves from half-filled to fully filled condition because convective mode of vibration is dependent on both the height of water filled and tank base diameter i.e h/D ratio which decreases as water level on tank increases.

2. Since most of codes gives the same value of Response reduction factor for similar type structures irrespective of time period of such structures. So the variation of Response reduction parameter with time period were observed for elevated water tank. Overstrength factor shows decreasing trend for increase in fundamental time period whereas ductility factor and Response Reduction factor shows increasing trend for increase in fundamental time period.

3. Response Reduction factor value for tank filled condition was found to be higher than that of tank empty condition. Similarly Response Reduction Factor shows increasing trend as hardness of soil increases and decreasing trend for increase in Seismic Zones of Earthquake

4. The range of Response reduction factor for 225 cumec capacity varies from 3.02 to $3.53,4.24$ to 4.73 and 4.77 to 5.33 for tank empty, tank half fill and tank full fill conditions, respectively for staging height varying from $12 \mathrm{~m}$ to $24 \mathrm{~m}$.

5. The range of response reduction factor for 450 cumec capacity varies from 4.72 to $5.66,5.61$ to 6.30 and 5.88 to 6.52 for tank empty, tank half fill and tank full fill conditions, respectively for staging height varying from $12 \mathrm{~m}$ to $24 \mathrm{~m}$.

6. Single value of overstrength, ductility and response reduction factor for similar Intze type elevated water tank cannot be justified

The conclusions are valid for the Intze type of elevated $\mathrm{RC}$ water tanks and other assumptions made in the study. Further investigations considering a wider set of geometrical parameters and higher number of models are required to ensure better performance evaluation.

\section{References}

[1] ATC 19 Structural Response Modification Factors, Applied Technology Council, Redwood city, California, 1995.
[2] ATC 40 Seismic Evaluation and Retrofit of Concrete Buildings, Applied Technology Council, Redwood city, California, 1996.

[3] FEMA 356 NEHRP Guidelines for the Seismic Rehabilitation of Buildings, Building Seismic Safety Council for the Federal Emergency Management Agency, Washington, D.C, 1997.

[4] IITK-GSDMA Guidelines for seismic design of liquid storage tanks, Indian Institute of Technology, Kanpur, India, 2005.

[5] IS 456 Indian Standard Plain and Reinforced ConcreteCode of Practice, Bureau of Indian Standards, India, 2000.

[6] IS 1893 (Part 1), Indian Standard Criteria for Earthquake Resistant Design of Structure (General Provisions and Buildings) Part I, Bureau of Indian Standards, New Delhi, 2002.

[7] IS 1893 (Part 2), Indian Standard Criteria for Earthquake Resistant Design of Structure (Liquid retaining tanks), Bureau of Indian Standards, New Delhi, 2014.

[8] IS 3370 (Part 2), Indian Standard Code of Practice of Concrete structure for storage of liquids, (Reinforced Concrete Structures), Bureau of Indian Standards, New Delhi, 2009.

[9] S. K. Jain SK and M. S. Medhekar, "Proposed provisions for a seismic design of liquid storage tanks," J. Struct. Engng., vol. 20, no. 3, 1993.

[10] S. K. Jain and S. U. Sameer, "Seismic design of frame staging for elevated water tanks" in Ninth Symposium on Earthquake Engineering (9SEE-90), 1990, vol. 1, no. 1.

[11] S. K. Jain and S. U. Sameer, "A review of requirements in Indian Codes for a seismic design of elevated water tanks," Bridge and Structural Engineer, vol. 23, no. 1, 1993.

[12] O. R. Jaiswal, D. C. Rai , S. K. Jain. Codal provision on seismic design for liquid storage tanks - A review (Report No. IITK GSDMA-EQ-01-V1.0), Indian Institute of Technology, Kanpur, 2004.

[13] O. R. Jaiswal and S. K. Jain, "Modified proposed provisions for a seismic design of liquid storage tanks: Part I-codal provisions," J. Struct. Engng., vol. 32, no. 3, pp. 297--310.

[14] G. W. Housner. "The dynamic behavior of water tanks," Bull Seismological Society of America, vol. 53, no. 2, pp. 381-387, 1963.

[15] M. H. Manek and D. K. Jivani, "A study on response reduction factor of $\mathrm{RC}$ water tank," Int J. Advance 
Engng. and Research Development, DOI:10.21090/IJAERD.020571, vol. 2, no. 5, pp. 493-504, 2015.

[16] Seismic Design of Buildings in Nepal, Nepal National Building Code NBC 105:2020.

[17] F. Omidinasab and H. Sakib, "Seismic vulnerability of elevated water tank using performance based design" in The 14th World Conf on Earthquake Engng, 2008.
[18] D. C. Rai, "Review of code design forces for shaft supports of elevated water tanks" in Proc 12th Symposium on Earthquake Engng, 2002, IIT Roorkee.

[19] P. L. N. Saroja and V. S. Rao, "Comparative study of analysis of elevated water tank due to earthquake from different zones of earthquake," Int. J. Constructive Research in Civil Engng. (IJCRCE), vol. 2, no. 1, pp. 22-29, 2016. 